\title{
Synthesis, Structural Characterization and DTA/TG Studies of a Schiff Base
}

\author{
Halime Güzin ASLAN*1
}

1Erciyes Üniversitesi, Fen Fakültesi, Kimya Bölümü, 38030, Kayseri

(Alınış / Received: 03.04.2017, Kabul / Accepted: 17.08.2017, Online Yayınlanma / Published Online: 13.10.2017)

Keywords

Sulphonamides,

DTA/TG,

Theorical ${ }^{1} \mathrm{H}$ NMR studies
Abstract: Our study contains a novel sulfonyl hydrazide. For this, N'-((1H-pyrrol-2yl)methylene)-N-methylbenzenesulfonohydrazide were synthesized. The structures of this new compound was characterized by elementary analysis, ${ }^{1} \mathrm{H}$ NMR, ${ }^{13} \mathrm{C}$ NMR, FT-IR, DTA/TG. Also this study is contain performed on optimized geometry at the B3LYP/6.311+G**level for this organic compounds.

\section{Yeni Bir Schiff Bazının Sentez, Yapısal Karektarizasyon, ${ }^{1}$ H NMR ve DTA/TG Çalışması}

Anahtar Kelimeler

Sülfonamidler,

DTA/TG,

Teorik ${ }^{1} \mathrm{H}$ NMR çalışması
Özet: Bu çalıșma yeni bir sülfonil hidrazit sentezini içermektedir. Bunun için N'((1H-pyrrol-2-yl)methylene)-N-methylbenzenesulfonohydrazide bileşiği sentezlenmiştir. Bu yeni bileşiğin yapısı elementel analiz, ${ }^{1} \mathrm{H}$ NMR, ${ }^{13} \mathrm{C}$ NMR, FT-IR, DTA/TG yöntemleri ile aydınlatılmıştır. Bu çalışma aynı zamanda bu organik bileşik için B3LYP/6.311+G** ${ }^{* *}$ seviyesinde optimize edilmiş yapıyı da içermektedir.

\section{Introduction}

Sulfonamides are the first group of drugs used to treat infections [1-3]. Usage areas have decreased after the first world war for bacteral resistance. However, the use of these compounds in pharmaceutical mixtures has increased their usefulness again. For example, Sulphadoxineprimetamine mixture is currently used in the treatment of malaria.

Also the mixture of sulfisoxazole-erythromycin is effective in ear infections, sulfamethoxazolthrimethoprim (Co-trimoxazole, Bactrim, Septrin) mixture are used in pneumonia, intestinal and urine infections. In recent years, rapidly developing computer-aided drug designs suggest that sulfonamides may have very different biological activities. Indeed, in 1998 Sildenafil Citrate (Viagra) [4,5], in 1999 protease Amprenavir [6,7], which is an inhibitor and used in the treatment of HIV, has been exported to the market. Besides these features, degradation steps in thermal processes are easily traceable. Schiff bases are some of the most widely used in this area.

Schiff bases are also used as catalysts, pigments and dyes, as polymer stabilisers, and intermediates in organic synthesis (8).

We have synthesized a new sulfonyl hydrazone compound (Schiff's base) due to its wide use in the health sector. Subsequently, we were characterised its structure by the FT-IR, ${ }^{1} \mathrm{H}$ NMR, ${ }^{13}$ C NMR, DTA/TG, and elemental analysis techniques. Also this compound's performed on optimized geometry at the B3LYP/6.311+G**level and HOMO - LUMO were calculated by the GAUSSIAN G03 software. The ${ }^{1} \mathrm{H}$ NMR chemical shifts of the compound were calculated by using the GIAO (Gauge Invariant Atomic Orbital) method in DMSO phases. All measured results were compared with the experimental data.

The general reaction of N'-( 1 H-pyrrol-2yl)methylene)-N-methylbenzenesulfonohydrazide are given in Figure 1.

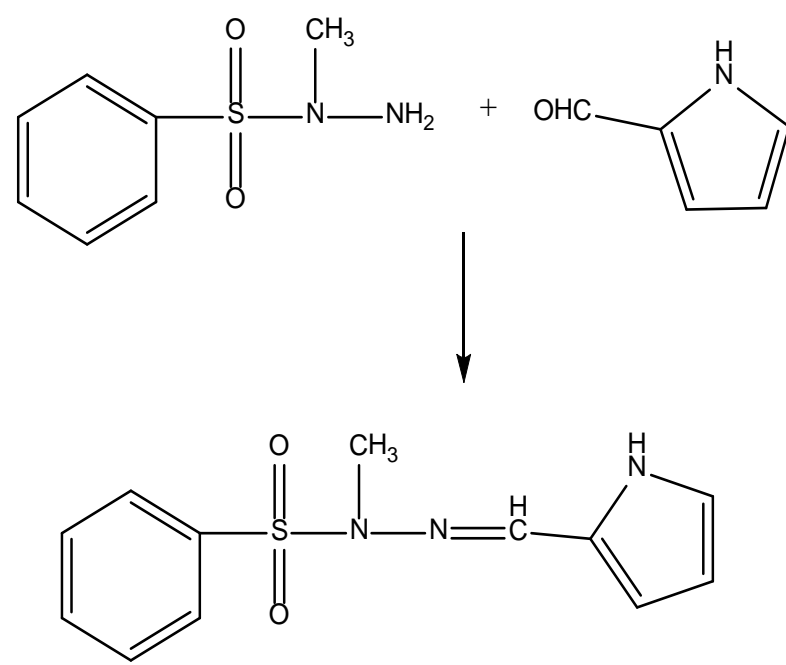

Figure 1. The general reaction schemes of N'-((1H-pyrrol2-yl)methylene)-N-methylbenzenesulfonohydrazide 


\section{Material and Method}

\subsection{Physical measurements}

The spectrophotometric measurements were made with the devices specified below; Mattson 1000 FTIR (ATR) spectrometer, Bruker $400 \mathrm{MHz}$ NMR spectrometer, Perkin Elmer Diamond TG/DTA thermal analyser opti melt 3 hot stage.

\subsection{General procedure for the synthesis}

\subsubsection{Synthesis of $\mathrm{N}^{\prime}-((1 \mathrm{H}-$ pyrrol-2-yl)methylene $)-$ $\mathrm{N}$-methylbenzenesulfonohydrazide}

A solution $\mathrm{N}$-methylbenzenesulfonohydrazide $(50$ mmol) in $5 \mathrm{ml}$ THF is mixed with a solution of 2pyrrol carbaldehyde in $5 \mathrm{ml} \mathrm{THF}$ and stirred at $0{ }^{\circ} \mathrm{C}$ for all day. The product is crystallised from ethanol three times. This resulted in a musty green solid which is stable at normal conditions and soluble in DMSO and DMF. Its details are as follows:

N'-((1H-pyrrol-2-yl)methylene)-N-

methylbenzenesulfonohydrazide: Musty green needles (EtOH) yield 62\%; mp $125 \quad{ }^{\circ} \mathrm{C}$ (disintegration); FT-IR $\gamma \max 3099(v(\mathrm{CH})$ aromatic), $2870\left(v_{\text {as }}\left(\mathrm{CH}_{3}\right)\right), 2818\left(v_{\mathrm{s}}\left(\mathrm{CH}_{3}\right)\right), \quad 1636(v(\mathrm{C}=\mathrm{N}))$, $1537(v$ (C-C) aromatic), $1449(\delta$ (C-H) aromatic in plane), $1335\left(v_{\text {as }}\left(\mathrm{SO}_{2}\right)\right), \quad 1265 \quad(v(\mathrm{C}-0))$, $1152\left(v_{\mathrm{s}}\left(\mathrm{SO}_{2}\right)\right), \mathrm{cm}^{-1}[9,10]$; ${ }^{1} \mathrm{H}$ NMR (DMSO $\mathrm{d}_{6}, 400$ $\mathrm{MHz}$ )( The proton number in the gaussian program is given as $\left.\mathrm{H}^{\prime}\right): \delta: 13.09\left(1 \mathrm{H}, \mathrm{s}, 31 \mathrm{H}^{\prime}\right), 12.24(1 \mathrm{H}, \mathrm{s}, 31$ $\left.\mathrm{H}^{\prime}\right), 11.92\left(1 \mathrm{H}, \mathrm{s}, 22 \mathrm{H}^{\prime}\right), 8.60\left(1 \mathrm{H}, \mathrm{t}, 9 \mathrm{H}^{\prime}\right), 7.88(1 \mathrm{H}, \mathrm{s}$, $\left.8 \mathrm{H}^{\prime}\right), 7.59\left(1 \mathrm{H}, \mathrm{d}, 11 \mathrm{H}^{\prime}, \mathrm{J}: 4 \mathrm{~Hz}\right), 7.39\left(1 \mathrm{H}, \mathrm{d}, 10 \mathrm{H}^{\prime}\right.$, $\mathrm{J}: 3.6 \mathrm{~Hz}), 7.10\left(1 \mathrm{H}, \mathrm{s}, 7 \mathrm{H}^{\prime}\right), 6.60\left(1 \mathrm{H}, \mathrm{d}, 26 \mathrm{H}^{\prime}, \mathrm{J}: 2 \mathrm{~Hz}\right)$, 2.59 (3H, d, 18,19,20 H', J: $4 \mathrm{~Hz}$ ). ${ }^{13} \mathrm{C}$ NMR (DMSO$\mathrm{d}_{6}, 400 \mathrm{MHz}$ ): $\delta: 151.09$ (C, 3C'), 137.46 (C, 6C'), 132.11 (C, 4C'), 128.95 (C, 23C'), 128.35 (C, 1C'), 128.13 (C, 5C'), 128.04 (C, 2C'), 156.15 (C, 21C'), 122.62 (C, 27C'), 114.18 (C, 25C'), 111.82 (C, 24C'), 35.97 (C, 17C'), Elementary Analysis(\%): Anal.Calcd for $\mathrm{C}_{12} \mathrm{H}_{13} \mathrm{~N}_{3} \mathrm{SO}_{2} ; \mathrm{C}: 54.74 ; \mathrm{N}: 15.96 ; \mathrm{H}: 4.98 ; \mathrm{S}: 12.18$;. Found: C:54.12; N:16.10; H:4.89;S:12.75.

\section{Results and Discussion}

The report presented, the synthesis and spectral characterisation of the N'-( $1 \mathrm{H}-$ pyrrol-2yl)methylene)- $\mathrm{N}$-methylbenzenesulfonohydrazide its thermal decomposition and theorical Gaussian ${ }^{1} \mathrm{H}$ NMR studies. The N'-((1H-pyrrol-2-yl)methylene)-Nmethylbenzenesulfonohydrazide molecule was optimized B3LYP 6.311 G $(d, p)$ basis set. The optimized figure of $\mathrm{N}^{\prime}-((1 \mathrm{H}-$ pyrrol-2-yl)methylene)$\mathrm{N}$-methylbenzenesulfonohydrazide $\left(\mathrm{C}_{12} \mathrm{H}_{13} \mathrm{~N}_{3} \mathrm{SO}_{2}\right)$ is given in Figure 2.

As given in the experimental section, all ${ }^{1} \mathrm{H}$ NMR, ${ }^{13} \mathrm{C}$ NMR and FT-IR data are consistent with our expectations.

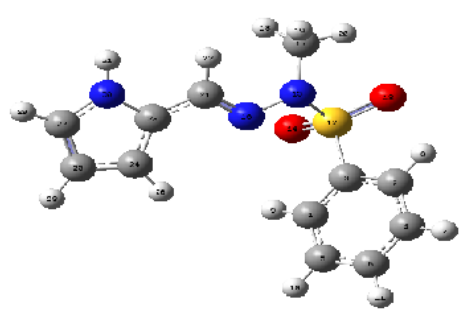

Figure 2. The optimized figure of $\mathrm{N}$--((1H-pyrrol-2yl)methylene)-N-methylbenzenesulfonohydrazide $\left(\mathrm{C}_{12} \mathrm{H}_{13} \mathrm{~N}_{3} \mathrm{SO}_{2}\right)$

The ${ }^{1} \mathrm{H} \quad \mathrm{NMR}$ spectrum of $\mathrm{N}$-((1H-pyrrol-2yl)methylene)- $\mathrm{N}$-methylbenzenesulfonohydrazide is given in Figure 3.

Also HOMO and LUMO were calculated. HOMO and LUMO are molecular orbital types. HOMO is the orbital with the highest paired electron. LUMO is the orbital with the lowest unpaired electron. The difference between the two orbital is called HOMOLUMO gap. This term can be used as an index of kinetic stability for a variety of aromatic hydrocarbons. In general, low value $(1,5 \mathrm{eV})$ is indicating that the compound is chemically active [9]. For this molecule, The HOMO-LUMO gap value is 3.00 $\mathrm{eV}$. By looking at this value, we can say that our molecule has a moderate chemical activity.

As shown in Figure 4, electron density of HOMO in molecule is mainly distributed in the whole structure except benzene ring but electron density of LUMO in molecule is distrubuted benzene ring and sulfonyl group. In this case, the molecule acts as an electron donor and an electron acceptor through these regions.

The N'-((1H-pyrrol-2-yl)methylene)-Nmethylbenzenesulfonohydrazide molecul ESP map is shown in Figure 3. The ESP map indicates the positive, negative, and neutral regions of the molecule. They showed that the positive region where preferred area for nucleophilic attact show as blue color, while the negative region where preferred area for electrophilic attack show as red color. From The N'-((1H-pyrrol-2-yl)methylene)-Nmethylbenzenesulfonohydrazide molecul ESP map, the sulfonyl group and pyrrole ring are suitable for electrophilic attack.

Theoretical ${ }^{1} \mathrm{H}$ NMR calculation was done in the gaussian program. Theoretical and experimental data are compared with each other. We observed a high agreement between the two data. However, pyrrol rings nitrogen and $-\mathrm{N}=\mathrm{CH}$ groups hydrogen chemical shifts differ from theoretical chemical shifts. The electronic charge density around of these atoms changes rapidly due to the influence of solvent effect. The chemical shift values of these hydrogens have been subtracted from the graph because of the above reason [9-11]. The correlation graph is shown in Figure 5. 


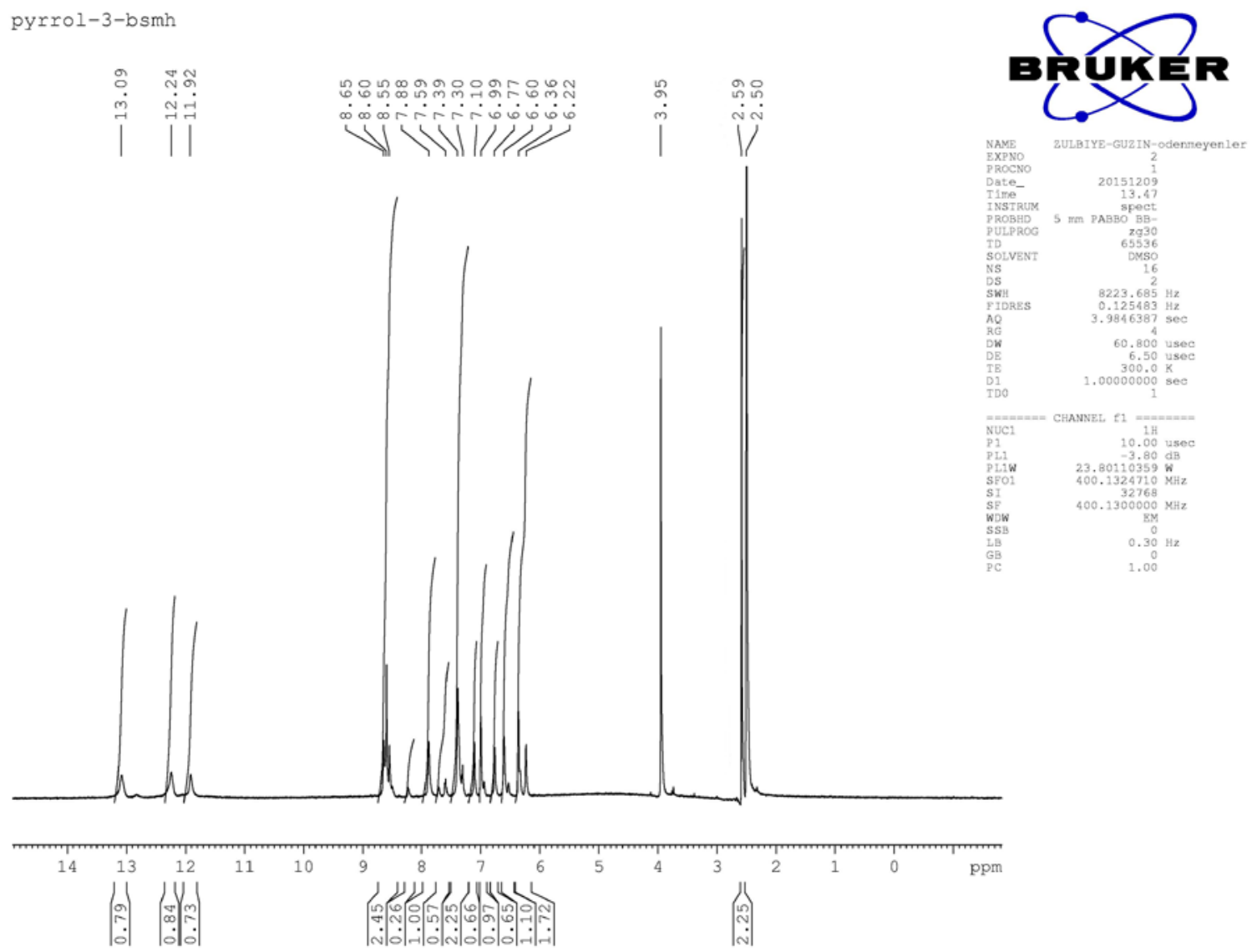

Figure 3. The ${ }^{1} \mathrm{H}$ NMR spectrum of N'-((1H-pyrrol-2-yl)methylene)-N-methylbenzenesulfonohydrazide

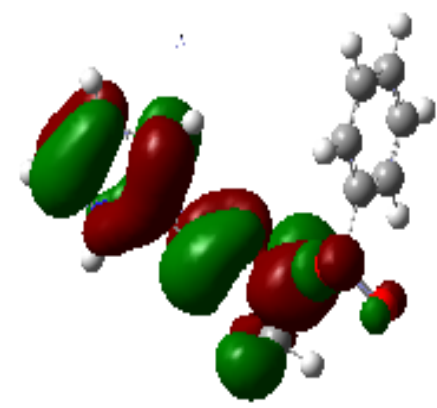

a) HOMO

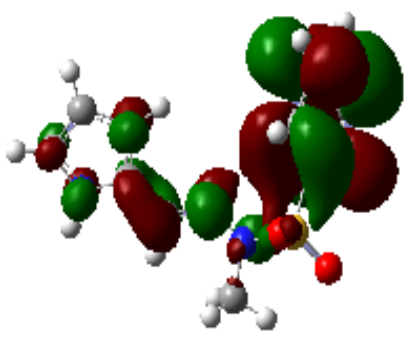

b)LUMO

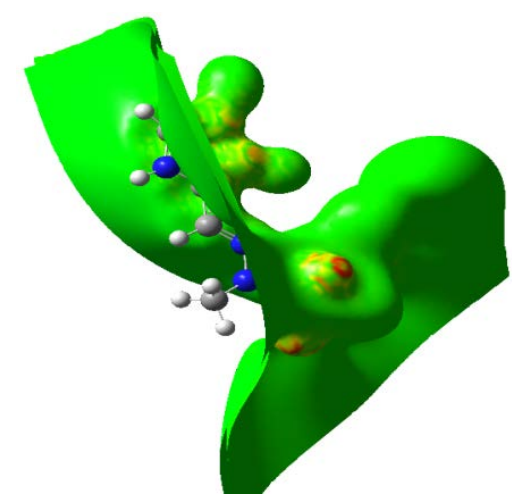

c) ESP Map

Figure 4. HOMO, LUMO and ESP map of The N'-((1H-pyrrol-2-yl)methylene)-N-methylbenzenesulfonohydrazide.

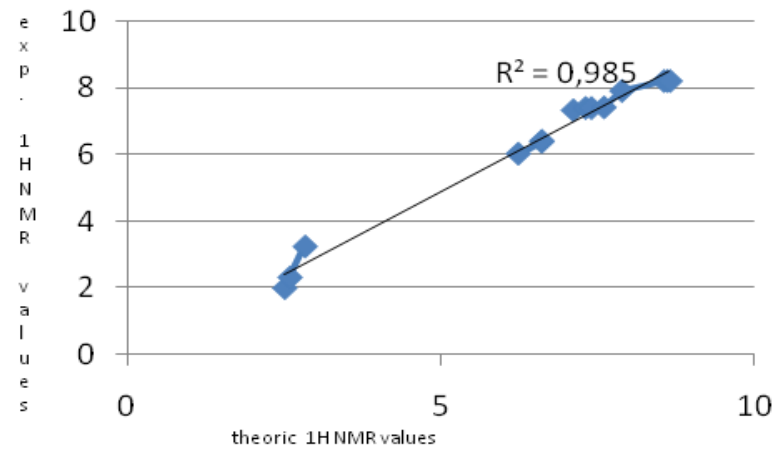

Figure 5. The correlation graph between theorical and experimental ${ }^{1} \mathrm{H}$ NMR data.

\subsection{Thermal studies}

The DTA / TG diagram shows that the compound is slightly moist. Thus, in the ${ }^{1} \mathrm{H}$ NMR diagram of the compound, very low-intensity ethyl alcohol peak is observed. This is followed by endothermic melting peak observed at around $136^{\circ} \mathrm{C}$. The intense peak at $334^{\circ} \mathrm{C}$ indicates that the decay has reached the highest point at this temperature. At this point, approximately $31 \%$ of the compound is degraded.

Based on this evidence, we can say that the imine bond is broken and the amine compound remains. 
The calculations show that the pyrrole aldehyde fraction accounts for $31 \%$ of the compound.

In the second part of the cleavage, the $-\mathrm{CH}_{3} \mathrm{NHNH}_{2}$ group may be separated from the main molecule.This peak observed at $522^{\circ} \mathrm{C}$. This fraction also accounts for $17 \%$ of the compound. The remainder of the compound may be referred to as benzene sulphonic acid. The temperature at which this compound begins to decompose strongly is approximately $870^{\circ} \mathrm{C}[14-$ 17].

The DTA/TG curves of the compound is shown in Figure 6.

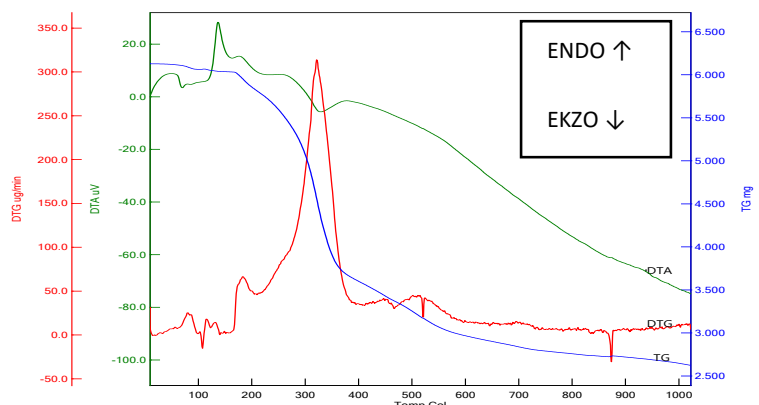

Figure 6. The DTA/TG diagram of N'-((1H-pyrrol-2yl)methylene)-N-methylbenzenesulfonohydrazide

\section{Conclusion}

In conclusion, 1 N'-((1H-pyrrol-2-yl)methylene)-Nmethylbenzenesulfonohydrazide was synthesised, and its theoric studies and DTA/TG studies were evaluated. From the thermal decomposition of compound $\mathrm{C}_{12} \mathrm{H}_{13} \mathrm{~N}_{3} \mathrm{SO}_{2}$ takes place in three stages. These complexes theoretical ${ }^{1} \mathrm{H}$ NMR studies were calculated using DFT/6.311(d,p) method. Comparasion of the experimental and the calculated data were in good agreement. we are planning to continue our studies by synthesizing new complexes from N'-((1H-pyrrol-2-yl)methylene)-Nmethylbenzenesulfonohydrazide molecule.

\section{References}

[1] Sneader, W. 1985. Drug Discovery: the evolution of modern medicines. Wiley-New York, 153-160, 217-219, 278-291.

[2] Hansch, C., Sammes, P.G., Taylor, J.B. 1990. In Comprehensive Medicinal Chemistry. Pergamon Press, Oxford, 2(7): 255.

[3] Dural, E. 2002. Farmakoloji. Nobel Tip Kitap, İstanbul, 454-457.

[4] Noss, M.B., Christ, G.J., Melman, A. 1999. Sildenafil: a new oral therapy for erectile Dysfunction. Drugs Today, 35(1999), 211-217.

[5] Brock, G. 2000. Sildenafil citrate. Drugs Today., 36(2000) 125-134.

[6] Adkins, J., Faulds, D., "Amprenavir", Drugs Today., 55(1998), 837-842.
[7] Conway, B., Shafran, S.D. 2000. Pharmacology and clinical experience with amprenavir. Opin.Invest. Drug, 9(2000), 371-382.

[8] Dhar, D.N., Sharma, R.L., Bansal, G.C. 1982. Gastrointestinal nematodes in sheep in Kashmir. Veterinary Parasitology, 11(1982), 271-277.

[9] Kesimli, B., Topacli, A. 2001. Infrared studies on Co and Cd complexes of Sulfamethoxazole. Spectrochim. Acta.57(2001), 1031-1036.

[10] Cami, G.E., Chufan, E.E., Pedregosa, J.C., Varetti, E.L. 2001. Infrared and Raman spectra of 5amino-1,3,4-thiadiazole-2- Experimental data and quantum chemistry calculations. J. Mol. Struc. 570(2001), 119-127.

[11] Sas, E.B., Kose, E., Kurt, M.,Karabacak M. 2015. FT-IR, FT-Raman, NMR and UV-VIS spectra and DFT calculations of 5-bromo-2ethoxyphenylboronic acid (monomer and dimer structures). Spectrochimica Acta Part A: Molecular and Biomolecular Spectroscopy. 137(2015), 1315-1333.

[12] Kurt, M.,Karabacak M., Okur, S., Sayın, S., Yılmaz, M. 2012. Sundaraganesan, N. Synthesis, FT-IR, FT-Raman, dispersive Raman and and NMR spectroscopic study of, host molecule which potential applications in sensor devices. Spectrochimica Acta Part A: Molecular and Biomolecular Spectroscopy. 137 (2012), 126133.

[13] Karabacak M., Kose, E., Sas, E.B., Kurt, M., Asiri, A.M., Atac, A. 2015. DFT calculations and experimental FT-IR, FT-Raman, NMR and UVVIS spectral studies of 3-fluorophenylboronic acid. Spectrochimica Acta Part A: Molecular and Biomolecular Spectroscopy. 136(2015), 306320.

[14] Cai L. F., Huang X. B., Rong M. Z., Ruan W. H., Zhang M. Q. 2006. Effect of grafted polymeric foaming agent on the structure and properties of nano-silica/ polypropylene composites. Polymer. 47(2006), 7043-7050.

[15] Cai L. F., Mai Y. L., Rong M. Z., Ruan W. H., Zhang M. Q. 2007. Interfacial effects in nanosilica/polypropylene composites fabricated by in-situ chemical blowing. Polymer Letters. 1(2007),2-7.

[16] Michalková A., Tunega D. 2007. Kaolinite:Dimethylsulfoxide Intercalate A Theoretical Study. J. Phys. Chem. 2007, 111 (2007), 11259-11266.

[17] Tian A.Q., Chen J.L.,Feng X., Wang W.Z., Wang L.Y. 2014. Thermal Behavior of Several Stable Hydroxyl_Free Radicals And Of Their Parent Hydrazines. Chinese J. Struct. Chem. Vol. 33(2014), 1443-1450. 